\title{
Inhibition of NETosis for treatment purposes: friend or foe?
}

\author{
Tahmineh Mohammadi Chamardani ${ }^{1} \cdot$ Samaneh Amiritavassoli ${ }^{1} \mathbb{C}$
}

Received: 28 July 2021 / Accepted: 25 November 2021 / Published online: 7 January 2022

(c) The Author(s), under exclusive licence to Springer Science+Business Media, LLC, part of Springer Nature 2021

\begin{abstract}
Active neutrophils participate in innate and adaptive immune responses through various mechanisms, one of the most important of which is the formation and release of neutrophil extracellular traps (NETs). The NETs are composed of network-like structures made of histone proteins, DNA and other released antibacterial proteins by activated neutrophils, and evidence suggests that in addition to the innate defense against infections, NETosis plays an important role in the pathogenesis of several other non-infectious pathological states, such as autoimmune diseases and even cancer. Therefore, targeting NET has become one of the important therapeutic approaches and has been considered by researchers. NET inhibitors or other molecules involved in the NET formation, such as the protein arginine deiminase 4 (PAD4) enzyme, an arginine-to-citrulline converter, participate in chromatin condensation and NET formation, is the basis of this therapeutic approach. The important point is whether complete inhibition of NETosis can be helpful because by inhibiting this mechanism, the activity of neutrophils is suppressed. In this review, the biology of NETosis and its role in the pathogenesis of some important diseases have been summarized, and the consequences of treatment based on inhibition of NET formation have been discussed.
\end{abstract}

Keywords NETosis $\cdot$ Inflammation $\cdot$ Autoimmunity $\cdot$ Treatment $\cdot$ NET inhibition

\section{Introduction}

Neutrophil Extracellular Traps (NETs) were discovered in 2004, and studies of these networked structures consisting of DNA, histones, fiber, and other antimicrobial proteins show that they can kill bacteria, viruses, fungi, and protozoa [1]. Trap them and lead them to immobility and then remove these pathogens by releasing antimicrobial proteins. This event is known as a relatively new innate immune response to infections [2-5]. Evidence suggests that in addition to participating in the innate defense against pathogenic microorganisms, NET can contribute to the pathogenesis and induction of some diseases such as rheumatoid arthritis (RA), diabetes, cystic fibrosis (CF), systemic lupus erythematosus (SLE), psoriasis ( $\mathrm{PsO}$ ) and metastatic malignancies [6]. Traces of NET have also been observed in some pathological phenomena such as periodontitis, vasculitis, thrombosis, coagulation disorders, metastasis, and atherosclerosis [7-11].

Samaneh Amiritavassoli

Samaneh.tavasoli@yahoo.com

1 Hormozgan University of Medical Sciences, Hormozgan, Iran
Following excessive NET formation and release of autoantigen, plasmacytoid dendritic cells (pDCs) can recognize the exposed autoantigens leading to interferon and autoantibody production, which are accompanied by tissue damage [12]. Therefore, regarding the pathologic role of NET formation, it has been considered more by researchers as an attractive therapeutic target [13]. In this context, the use of NET inhibitors has been investigated in various studies [14-16]. NET can also be indirectly targeted and reserved by inhibition of protein arginine deiminase 4 (PAD4), Myeloperoxidase (MPO), and neutrophilic elastase [12]. Studies in animal models of inflammation as well as human respiratory disorders showed that inhibition of MPO and neutrophilic elastase significantly reduced neutrophil-mediated inflammation $[17,18]$.

Various inhibitors have been studied in the treatment of diseases, some of which, such as rituximab, indirectly inhibit NET and lead to a decrease in the autoantibody titer in autoimmune diseases, and others, such as $\mathrm{F}$ - and $\mathrm{Cl}$-amide can directly inhibit NET formation, reducing destructive inflammatory response $[19,20]$. Although the use of this therapeutic strategy has advantages in the treatment of some disorders that are Net-mediated, on the other hand, studies on animal models show that complete inhibition of NET 
can increase the susceptibility to infections and loss of neutrophil functions involved in innate immune responses [21, 22]. Therefore, this review summarized the various aspects of targeting NET as a therapeutic option as well as its advantages and disadvantages.

\section{NETosis biology}

NETosis is the extrude NETs by activated neutrophils, an innate defense against pathogens, and it has been revealed that a variety of signals and biological phenomenon can participate in NET formation [23-25]. Evidence suggests that the production of neutrophil elastase, MPO, reactive oxygen species (ROS), histone modification, and chromatin decondensation are the key events leading to NET formation $[23,26]$. It has been demonstrated that following activation of NADPH oxidase 2 (NOX2), superoxide anions and hydrogen peroxide are produced, which are important in the NET formation. Hydrogen peroxide is considered a substrate for MPO, stimulating the production and release of elastase from neutrophil granules [27]. Consequently, the migration of elastase into neutrophil nuclei leads to chromatin decondensation. However, the exact mechanism has not yet been fully elucidated [28]. After decondensation and decomposition of chromatin, the integrity of the nuclear membrane is disturbed, leading to the formation of a high stability network containing chromatin, granular and cytosolic proteins, elastase and MPO, which are able to exert their antibacterial properties following rupture of the neutrophil membrane and excretion outside the cell [29, 30] (Fig. 1).

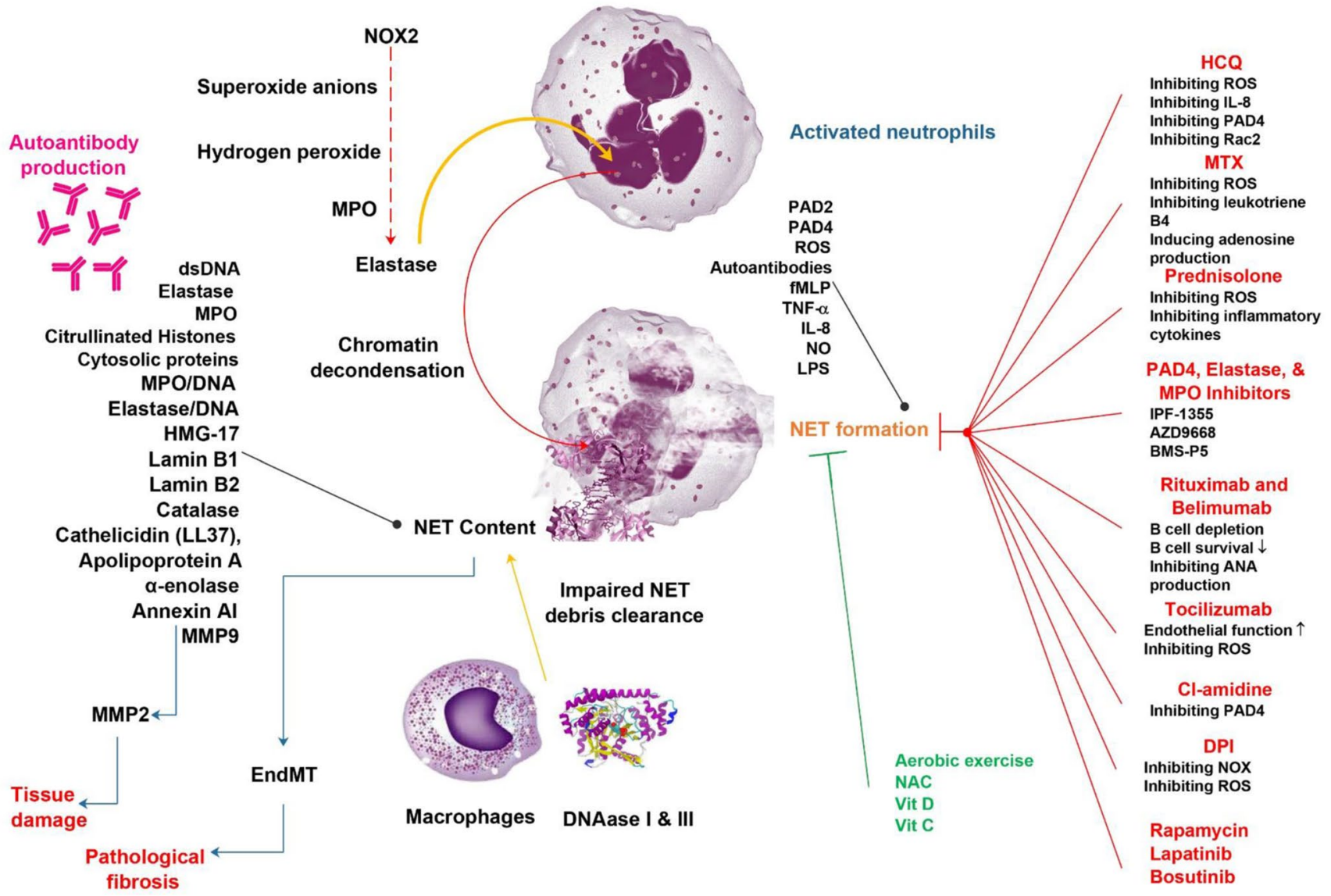

Fig. 1 NETosis consequences and NET inhibition. As the figure displays, many factors can induce. NET formation stimulators, including PADs, ROS, autoantibodies, fMLP, NO, LPS, IL-8, and TNF- $\alpha$. Following these events, the contents of the NET are released, and due to the lack of proper clearance by macrophages as well as defects in DNase enzymes, the NET-derived debris (NET contents in the figure) are exposed to the immune system and are identified as autoantigens, resulting in autoantibody production, increased inflammation, tissue damage, and pathologic fibrosis. On the other hand, using NET for- mation inhibitors can be used to treat various NET-related diseases through various mechanisms such as inhibition of PADs, ROS production, and production of inflammatory mediators. $H C Q$ hydroxychloroquine, MTX methotrexate, $R O S$ reactive oxygen species, $P A D$ protein arginine deiminase, $M P O$ myeloperoxidase, $N O X$ NADPH oxidase, NET neutrophil extracellular trap, $M M P$ matrix metallopeptidase, $f M L P \mathrm{~N}$-formylmethionyl-leucyl-phenylalanine, TNF tumor necrosis factor, $I L$ interleukin, EndMT endothelial-to-mesenchymal transition, $N O$ nitric oxide, LPS Lipopolysaccharides 
Studies show that due to differences between in vitro and in vivo conditions, NET formation is different in each of these conditions. For instance, the citrullination of histones by PAD4 and the subsequent unwrapping of the nucleosome are considered the NET formation's main events in vivo [31, 32]. In fact, NETosis is a type of programmed cell death different from necrosis and apoptosis, characterized by the release and exposure of the decondensed chromatin and the release of neutrophil granule content into the extracellular environment [33]. As discussed, various biological events play a role in NET formation via neutrophil activation. One of these events is the activation and function of the NOX2 enzyme to produce ROS or chromatin decondensation [34]. Citrullination of histone proteins by PAD4 is another vital bioevent that makes them suitable targets for treatment [35].

Moreover, post-translational modifications occurred in NET decorating proteins such as acetylation, citrullination, and methylation of histones. The mentioned modifications indicated that NETs could be a source of intracellular autoantigens in ADs [31, 36, 37]. Besides, due to the low number of mitochondria in neutrophils, NETs derived from mitochondrial DNA or mtDNA are probably very low [38, 39]. Based on studies in the field of NETosis, it has been determined that there are two types of NETosis, one is "suicide" or NOX2-dependent, which lasts about $3 \mathrm{~h}$, and the other is "vital" or NOX2-independent that the formation of this antimicrobial network takes about $30 \mathrm{~min}$ and neutrophils can exert their antibacterial effects despite maintaining their structure. It has been demonstrated that calcium-activated vital NETosis is fast and mediated by mitochondrial ROS and calcium-activated small conductance potassium (SK) channel member SK3 [40]. Another difference between these two types of NETosis is that the vital type does not require NOX2 and MPO because only stimulation by the pathogenic bacterium is sufficient to induce this type of NETosis [41, 42]. It has been reported that several inflammatory mediators can stimulate NET release, including $\mathrm{N}$-formylmethionyl-leucyl-phenylalanine (fMLP), tumor necrosis factor- $\alpha(\mathrm{TNF} \alpha)$, interleukin-8 (IL-8, CXCL8), lipopolysaccharides (LPS), and nitric oxide (NO) [43].

\section{Physiologic and pathologic roles of NETosis}

NETosis is an innate immune response against pathogenic microorganisms that eliminates pathogens via trapping and releasing antibacterial enzymes and free radicals [44]. As an innate immune cells, neutrophils are the first cells to migrate to the site of infection to control the spreading of the infectious agent through phagocytosis, secretion of inflammatory cytokines, and NET formation [41]. Studies show that other granulocytes such as macrophages can trap and immobilize microbes in addition to neutrophils by releasing decondensed chromatin [45]. In the homeostasis phase, clearance of the infection environment of cellular debris and NETs is vital [46]. Studies show that NETs are degraded by plasma DNA-degrading enzymes and then cleared by macrophages [47]. In mice, DNase (I and III) enzymes are deficient; following infection and activation of neutrophils, the animals die after a few days due to the deposition of NETs [48]. Furthermore, NETs are identified as intracellular autoantigens and recognized by the immune system, which is the basis of autoimmune diseases $[49,50]$. In this section, the role of NETosis in some important diseases is reviewed.

\section{Sepsis}

Circulating NETs are also detected in patients with sepsis accompany poor multi-organ failure and poor clinical outcome [51-53]. Uncontrollable increase in NET formation, apoptosis, necrosis and, on the other hand, lack of clearance and degradation of cell death-derived debris and NET contents, including cell-free DNA, leads to increased expression of inflammatory mediators such as TNF- $\alpha$ in these patients. It has also been reported that NET-derived citrulline histones can act as damage-associated molecular patterns (DAMPs) by inducing the expression of inflammatory cytokines and disrupting endothelial cell function through cytotoxicity and increasing ROS production, resulting in multi-organ damage [54-56].

\section{SLE}

A study on RA and SLE patients reported that in $79 \%$ of the patients, NET-associated autoantigens including MPO/ DNA and elastase/DNA complexes were detected, and the activated NETosis in these patients was detected NOX2independent [57]. In patients with systemic lupus erythematosus (SLE), it has been reported that there is a significant association between disease severity and decreased DNases activity and the number of NET complexes (double-stranded DNA and post-translationally modified proteins) in the blood [58]. Following the exposure of NET-associated autoantigens, interferon (IFN)-producing pDCs activated, resulting in endothelial tissues and organs injury [59, 60]. Activated neutrophils that produce NETs are detected in SLE patients, and in vitro studies show that sera obtained from these patients can react with NET components including DNA, elastase, MPO, and citrullinated $\mathrm{H} 3$ histones, suggesting the presence of autoantibodies against the mentioned autoantigens [37, 61, 62]. NET components have also been observed in cutaneous lesions and kidneys of patients with SLE [60, 63]. As mentioned, autoantibodies play an important role in the pathogenesis of SLE and based on the laboratory findings, most SLE patients are positive for antinuclear antibodies (ANA) or anti-dsDNA [64]. 
Furthermore, anti-histone autoantibodies are also common in these patients [65]. In addition to anti-dsDNA and histone autoantibodies in SLE patients, autoantibodies against other NET components including high-mobilitygroup protein 17 (HMG-17), lamin B1, lamin B2, catalase, cathelicidin (LL37), apolipoprotein A, $\alpha$-enolase, and annexin AI have been rarely detected $[12,66]$. It is also noteworthy that NET proteins in SLE patients can contribute to tissue damage. One of the contents of NET is matrix metallopeptidase 9 (MMP9), which can induce vascular damage and endothelial cell apoptosis by MMP2 activation [67]. Excessive production of NET in glomeruli and lack of effective clearance of its residues also leads to vascular leakage and stimulation of the endothelial-to-mesenchymal transition (EndMT), which is involved in developing pathological fibrosis [68].

On the other hand, the deposition of the autoantibody/ NET protein complexes and in the glomerulus of SLE patients leads to lupus nephritis [69]. These complexes can activate the complement system and lead to infiltrated leukocytes that express Fc $\gamma$ and complement receptors. Activation of these leukocytes leads to ROS production and degranulation of proteases and tissue damage [70, 71].

\section{RA}

Evidence suggests that NET debris has been observed in RA patients' synovial fluid and serum [57, 72]. Synovial biopsy tissue staining also showed the presence of CD15, elastase, MPO and citrulline histone $\mathrm{H} 3$ as NET products in these patients $[73,74]$. In RA, the enzymes PAD2 and PAD4 are responsible for the citrullination of a wide range of proteins detected by autoantibodies such as actin, histone H1.3, histone H3, vimentin, and $\alpha$-enolase [66]. NET-derived neutrophil products including PAD2 and PAD4 along with MPO, neutrophil gelatinase-associated lipocalin (NGAL), annexin-A1, cathepsin $\mathrm{G}$, and other citrulline proteins can be detected in the synovial fluid and also synovial necrotic regions of RA patients [75, 76]. Joint damage and increased disease activity due to NETosis in RA also occurred with different mechanisms. An animal study in transgenic HLADRB $1{ }^{*}$ 04:01 mice showed elastase could disrupt the cartilage matrix's biostructure and induce PAD2 production by fibroblast-like synoviocytes (FLS). FLS can internalize cartilage fragments and present them to $\mathrm{T}$ cells via major histocompatibility complex (MHC) class II.

Moreover, PAD2 is responsible for the citrullination of cartilage fragments. After recognizing the presented autoantigen, $\mathrm{T}$ cells help produce anti-citrullinated protein antibodies (ACPA) by autoreactive B cells [77, 78]. On the other hand, MMP8 and MMP9 as NET proteins produced in RA participate in the degradation of the cartilage matrix $[79,80]$. Aggrecan is another major component of cartilage biostructure, and its degrading enzymes can be detected in NET contents [78]. Following citrullination of aggrecan fragments, they presented to autoreactive $\mathrm{T}$ cells, which induce the production of wind autoantibodies [78]. Furthermore, produced autoantibodies by synovial autoreactive B cells as well as NETs produced by blood and synovial neutrophils together lead to joint damage [81].

\section{Cancer}

Another pathological condition is malignancy, which according to studies in this field, the NET formation can also play a role in cancer pathogenesis $[82,83]$. Evidence demonstrated that both animal cancer models and patients with malignancy had recognized NETs in the blood and tumor tissue. NETosis can play a pro-tumor or anti-tumor role, depending on the condition and the existing signals of the tumor microenvironment (TME) [25, 84]. In fact, according to previous studies, NETosis is associated with increased tumor cell proliferation, tumor progression, and metastasis due to the presence of various proteases as well as inducer signals in NET contents that stimulate tumor cells. On the other hand, tumor cells induce NET formation through the release of various mediators. In addition, the presence of tumor-associated neutrophils (TANs) in the TME can also be associated with tumor growth and development $[6,85]$. In the TME, the release of IL- 8 and granulocyte-colony-stimulating factor (G-CSF) produced by tumor cells can induce NETosis. G-CSF produced by cancer cells as a granulocyte growth factor increases neutrophils, followed by increased production of ROS and NETosis [85-88]. The outcomes of in vitro studies also show that the co-culture of neutrophilactivated endothelial cells increases NETosis via IL-8 produced by endothelial cells. The findings also show that these cancer cells increase NET formation by neutrophils by priming platelets in pancreatic cancer [89].

\section{Heart failure and cardiomyopathy}

It has been documented that several NET-related heart and systemic diseases including, atrial fibrillation, myocardial infarction (MI), hypertrophic cardiomyopathy, myocarditis, diabetes, chronic kidney disease, chronic obstructive pulmonary disease, and autoimmune diseases, could be cause heart failure [90]. Based on available knowledge, NETs may be accompanied by aseptic inflammation and microthrombosis, inducing myocardial ischemia-reperfusion (I/R) and MI [91]. Moreover, citrullinated histone H3, dsDNA, and neutrophil elastase levels increased in the culprit lesion site of patients with ST-segment elevation MI (STEMI) compared with the femoral site $[92,93]$. These findings indicated that NET components are related to ventricular function, infarcted size, and clinical consequences in patients with 
STEMI [69]. It has also been reported that patients with a high serum neutrophil-to-lymphocyte ratio (NLR) are significantly more susceptible to developing atrial fibrillation [94-96]. Pre-clinical and clinical studies demonstrated that neutrophil MPO is involved in the pathogenesis of atrial fibrillation. For instance, MPO deficient mice were protected from atrial fibrillation, and the protective condition was reversed following MPO restoration. These outcomes disclosed that MPO could be involved in myocardial remodeling, increasing susceptibility to atrial fibrillation [97]. Furthermore, a study on a hypertrophic and hypertensive cardiomyopathy mice model under treatment with transverse aortic constriction (TAC) showed that Wnt5a-mediated neutrophils infiltration into the heart of animals could lead to the NET formation, hyperinflammation and cardiac fibrosis and dysfunction [98]. Current studies reported that neutrophils might be involved in the pathogenesis of atherosclerosis and venous thromboembolism (VTE). However, the role of these cells and NETosis in atherosclerosis has been less studied, and most studies focused on macrophages and their involvement in vascular plaque destabilization. Recently, it has been revealed that NET formation may be involved in the development of atherosclerosis because, in patients with acute myocardial infarction, the presence of NET contents in the lumen of atherosclerotic arteries has been detected. The production of debris from various programmed cell death mechanisms in atherosclerosis, such as apoptosis, NETosis, and efferocytosis and lack of clearance and degradation of these fragments, may cause inflammation and disease progression [99]. Furthermore, NETs can tempt endothelial dysfunction and initiate inflammatory immune responses, resulting in venous thrombi and atherosclerotic plaques formation [100]. However, another experimental investigation in this field suggested that NET-derived PAD4 and bone marrow-derived cells cannot impact chronic atherogenesis, but it can contribute to the formation of acute thrombotic lesions [101].

\section{Diabetes}

NETosis is a major involved factor in the pathogenesis of various diabetes and diabetes-associated complications. In type 1 diabetes, the death of pancreatic beta cells leads to the infiltration of neutrophils into the pancreas, which leads to the activation of neutrophils and NET formation. In type 2 diabetes, an increase in the NET formation, followed by an increase in the release of NET content, has been observed. For example, dsDNA has been accompanying an increased susceptibility to cardiovascular disease and diabetic-related kidney disorders. NETosis has also been disclosed to be involved in diabetic retinopathy and impaired wound healing. The mechanism of inducing NETosis in diabetes is not yet fully understood, but hyperglycemia is an important trigger for NET formation. However, an increase in NETosis is also seen in patients with controlled glucose levels [102].

\section{Periodontitis}

In humans, periodontitis is one of the most common inflammatory, infectious diseases, often occurring in subgingival plaque due to uncontrolled responses of activated neutrophils to pathogenic bacteria. As a result, neutrophils are considered to be the main immune cells in the pathogenies of periodontitis. Once activated by pathogens, neutrophils can produce ROS, which stimulates NETosis. NET formation appears to act as a double-edged sword in periodontitis because it can control infection by trapping pathogenic bacteria and cause autoimmunity and destructive immune system responses through its autoantigens contents [10]. This suggests that adequate NET formation and its content are vital for periodontal health preservation [103].

\section{Acute respiratory distress syndrome (ARDS)}

Evidence suggests that neutrophil infiltration into the lungs and NET formation cause hyperinflammation in the lungs, and the rate of this infiltration and NET production is directly related to the severity of the disease [104]. Correspondingly, studies on animal models of acute lung injury (ALI) have shown that neutrophil depilation can have a protective effect against destructive neutrophil-mediated inflammatory responses [105]. In ventilator-induced lung injury (VILI), amplified levels of high-mobility-group box protein 1 (HMGB1) and IL- $1 \beta$ could induce NET formation [106, 107]. Mechanical deformation of pulmonary cells could stimulate phosphoinositide 3-kinase gamma (PI3K $\gamma$ )mediated pathway, regulating pulmonary cells apoptosis and neutrophil-mediated inflammatory response via the phosphorylation of ERK1/2 and Akt [108]. Moreover, neutrophil-macrophage cooperation was detected in liver injury, atherosclerosis, kidney diseases, hematological disorders and inflammatory bowel disease (IBD) [109-112]. In addition, it has been shown that in ARDS, there is a significant association between infiltrated neutrophils, resident alveolar macrophages, and increase of caspase- 1 levels as well as IL- $1 \beta$ production. In this context, it has been reported that pyroptotic alveolar macrophages are responsible for releasing caspase- 1 and IL- $1 \beta$ and eventually neutrophil-derived NET and developing ARDS [113].

\section{COVID-19}

Recent studies on coronavirus disease 2019 (COVID-19) showed that viral pneumonia leads to respiratory failure and multi-organ failure due to dysregulated inflammation, complement activation, and thrombosis [114, 115]. Moreover, 
Table 1 Potential anti NETs therapeutics and mechanism of action

\begin{tabular}{|c|c|c|c|c|}
\hline Pharmacological compounds & Type of study & Target & Mechanism of action & References \\
\hline Hydroxychloroquine & Pre-clinical & Inhibiting NET formation & $\begin{array}{l}\text { Inhibiting TLR-9, ROS, and IL-8 } \\
\text { production expression of PAD4 } \\
\text { and Rac2 }\end{array}$ & {$[16,121]$} \\
\hline Methotrexate & Pre-clinical/clinical & $\begin{array}{l}\text { Inhibiting ROS/adenosine produc- } \\
\text { tion }\end{array}$ & Indirectly inhibit NET production & {$[127-132]$} \\
\hline Prednisolone & Pre-clinical & $\begin{array}{l}\text { Inhibiting production of ROS and } \\
\text { inflammatory mediators }\end{array}$ & Indirectly inhibit NET production & {$[134]$} \\
\hline PF-1355 & Pre-clinical & Inhibiting MPO & Inhibiting NET and IC formation & {$[17]$} \\
\hline AZD9668 & Clinical & $\begin{array}{l}\text { Inhibiting neutrophil elastase/IL-1 } \beta \\
\text { IL-6, IL-8, TNF } \alpha\end{array}$ & Indirectly inhibit NET production & {$[18]$} \\
\hline BMS-P5 & Pre-clinical & Inhibiting PAD & Indirectly inhibit NET production & {$[136,137]$} \\
\hline Rituximab and Belimumab & Clinical & Anti-CD20 and BlyS & $\begin{array}{l}\text { B cells depletion, indirectly inhibit } \\
\text { NET production }\end{array}$ & {$[15]$} \\
\hline Tocilizumab & Pre-clinical/clinical & Anti-IL-6R & Indirectly inhibit NET production & [145] \\
\hline Cl-amidine & Pre-clinical & Inhibiting PAD4 & $\begin{array}{l}\text { Indirectly inhibit NET production, } \\
\text { decreasing atherosclerotic lesion } \\
\text { area, reducing thrombosis }\end{array}$ & {$[146]$} \\
\hline DPI & Pre-clinical & $\begin{array}{l}\text { Inhibiting gluconeogenesis and } \\
\text { cellular respiration enzymes, } \\
\text { inhibiting ROS production }\end{array}$ & Indirectly inhibit NET production & {$[149,150]$} \\
\hline Recombinant human DNase & Pre-clinical & NET-derived DNA & $\begin{array}{l}\text { Reduce their destructive effects of } \\
\text { NET contents }\end{array}$ & {$[168,169]$} \\
\hline Azithromycin and chloramphenicol & Pre-clinical & $\begin{array}{l}\text { Affect respiratory burst, apoptosis, } \\
\text { degranulation of neutrophils }\end{array}$ & Indirectly inhibit NET production & [173] \\
\hline THIQs & Pre-clinical & Neutrophils & $\begin{array}{l}\text { Inhibiting different stages of NET } \\
\text { formation without weakening } \\
\text { neutrophil normal functions }\end{array}$ & {$[175]$} \\
\hline Anthracyclines & Pre-clinical & $\begin{array}{l}\text { Inhibiting of transcription initiation } \\
\text { or DNA replication }\end{array}$ & Inhibiting NET formation & {$[177]$} \\
\hline
\end{tabular}

$N E T S$ neutrophil extracellular traps, $I L$ Interleukin, $R O S$ reactive oxygen spices, $T L R$ toll-like receptor, $P A D$ protein arginine deiminase $4, B l y S$ B lymphocyte stimulator, $T H I Q s$ tetrahydroisoquinoline derivatives, $I L-6 R$ interleukin-6 receptor

active neutrophils play an important role in the pathogenesis of this disease, and an increase in the number of neutrophils along with a decrease in lymphocytes is evident in COVID-19 patients [115]. As discussed before, NET formation increases the inflammatory response and vascular micro-thrombosis due to the deposition of NET components, which in the lungs of patients leads to ARDS [116]. Studies have also reported that MPO/DNA complexes, cell-free DNA, and citrullinated histones, especially $\mathrm{H} 3$ as major NET components, can be detected in the serum of patients with COVID-19. On the other hand, in these patients, there is a positive and significant association between the levels of cell-free DNA and C-reactive protein (CRP), D-dimer, lactate dehydrogenase (LDH), as well as neutrophil count [117]. There is also a correlation between citrullinated $\mathrm{H} 3$ and platelet count, indicating the role of NETosis in thrombosis formation.

Furthermore, cell-free DNA and MPO/DNA levels were higher in patients under intensive care, and mechanical ventilation than in other patients admitted with breathing room air. As a result, NETosis may also be associated with disease severity in COVID-19. It has also revealed that COVID-19 patients' sera can activate neutrophils and NET formation in vitro [117].

\section{NET inhibitors}

One of the therapeutic approaches in autoimmune and inflammatory diseases, as well as metastatic cancers in which traces of NETosis have been found, is the use of NET inhibitors or enzymes involved in the NET formation such as PAD4 and MPO (Table 1). In this section, the most important NET inhibitors are briefly reviewed (Fig. 1).

\section{Hydroxychloroquine}

Hydroxychloroquine is an anti-malarial drug widely used to treat some diseases such as SLE, RA and COVID-19 [118-120]. This drug can inhibit the function of activated 
neutrophils. Hydroxychloroquine has been shown to inhibit NET formation by inhibiting toll-like receptor-9 (TLR-9), inhibiting ROS, and preventing IL-8 production. Furthermore, hydroxychloroquine can inhibit the expression of PAD4 and Rac2 [16, 121]. In animal models of hepatic ischemia/reperfusion injury, treating animals with hydroxychloroquine could repress the production of NETs [16]. However, the results of some studies have been contradictory and have confirmed that hydroxychloroquine does not affect the expression of PAD4, MPO and neutrophilic elastase [122]. Several studies have proved that autophagy is closely connected to the platelet-induced NET formation, and the administration of hydroxychloroquine as an autophagy inhibitor in patients with COVID-19 could reduce immunothrombosis through inhibition NETosis [123-125].

\section{Methotrexate}

Methotrexate has been used in clinics for over 30 years as a first-line drug in the treatment of RA [126]. In addition to $\mathrm{RA}$, it is also prescribed in SLE and can inhibit cytokinedelayed neutrophil apoptosis. It also can inhibit ROS production and leukotriene B4 synthesis [127-129]. As discussed, ROS is involved in the NET formation, so methotrexate can indirectly inhibit NET production by neutrophils. A recent study in patients with COVID19 showed that methotrexate could reduce inflammation by inducing adenosine production [130]. Adenosine is an immunomodulator that can also inhibit NETosis and thrombosis [131, 132].

\section{Prednisolone}

An active metabolite of prednisone known as prednisolone is widely used as a corticosteroid to treat inflammatory and autoimmune diseases. Following crossing the cell membrane and entering the cytoplasm, prednisolone can bind to glucocorticoid receptors and following this ligation, the complex can directly disrupt gene expression of enzymes and inflammatory cytokines. Furthermore, prednisone is able to rapidly inhibit the function of neutrophils, such as the production of ROS and inflammatory mediators, thereby disrupting NET formation [133, 134].

\section{PAD4, elastase and MPO inhibitors}

As mentioned in the mechanisms of NET formation, elastase and MPO enzymes are involved in the decoding of chromatin by neutrophils and their release. Therefore, inhibition of these enzymes can inhibit NETosis. An investigation on vasculitis mouse models using a 2-thiouracil mechanism-based MPO inhibitor (PF-1355 [2-(6-(2,5-dimethoxyphenyl)4-oxo-2-thioxo-3,4-dihydropyrimidin-1(2H)-yl) acetamide) showed that MPO activity is involved in NETosis and immune complex (IC)-associated vasculitis. The findings revealed that PF-1355 could inhibit MPO and further NET and IC formation in vasculitis [17]. AZD9668 is known as an effective and reversible neutrophil elastase inhibitor [135]. A study on bronchiectasis patients showed that administration of AZD9668 could prevent inflammation by reducing the expression of elastase, IL-1 $\beta$ IL-6, IL- 8 , TNF $\alpha$, resulting in improved lung function with minimum side effects [18]. However, due to the variability of the outcomes of studies in this field, enzyme inhibitors involved in NET formation need further studies. Moreover, it has been demonstrated that human and murine multiple myeloma cells can induce citrullination of histone $\mathrm{H} 3$ and NET formation. These occurrences could be inhibited through pharmacological targeting of PAD4 with BMS-P5, a novel and specific small PAD4 inhibitor molecule [136, 137].

\section{Rituximab and belimumab}

It has been reported that ICs in vitro can trigger NET formation whereas NET-derived DNA is considered as an autoantigen for ANAs in SLE [138]. In this context, rituximab (anti-CD20 mAb) depletes autoreactive B cells and inhibits further autoantibody production [139]. Moreover, belimumab (fully human $\mathrm{IgG} 1 \lambda$ recombinant $\mathrm{mAB}$ ) can target BlyS and reduce autoreactive B cells' survival and autoantibodies production [140]. Interestingly, an investigation showed that a combination of rituximab and belimumab reduces the NET formation and ANA production in SLE patients [15]. Thus, the combination of these mAbs can inhibit NET formation in parallel with the depletion and inhibition of B cells, which play a major role in producing autoantibodies against NET-derived autoantigens.

\section{Tocilizumab}

Tocilizumab is a mAb against IL-6 receptor (IL-6R) widely used to treat inflammatory diseases such as RA, SLE, COVID-19, and even cancer [141-144]. A study on a total $\mathrm{f}$ twenty RA patients six months under treatment with 162 mg per week subcutaneous tocilizumab showed that it could enhance endothelial function and decrease leukocytesderived oxidative stress. Furthermore, tocilizumab decreased the frequency of low-density granulocytes and inhibited NET formation. These findings were also confirmed after treatment of neutrophils and monocytes with tocilizumab in vitro. This study also showed that pro-atherothrombotic complications might be reduced in RA patients following inhibition of NETosis. [145]. 


\section{Cl-amidine}

Inhibition of peptidyl arginine deiminase by $\mathrm{Cl}$-amidine is a therapeutic approach that can reduce or inhibit NET formation in vivo. It has been reported that in murine models of atherosclerosis treated for 11 weeks with daily injections of $\mathrm{Cl}$-amidine could inhibit NET formation by inhibiting PAD4 and decreasing atherosclerotic lesion area, and reducing thrombosis. These consequences support a role for abnormal NET formation in atherosclerosis pathogenesis [146].

\section{Diphenyleneiodonium chloride (DPI)}

DPI is a blood glucose control agent that exerts its effects by inhibiting gluconeogenesis and cellular respiration enzymes, including NO synthase, NOX, xanthine oxidase, cholinesterase, and NADPH cytochrome P450 oxidoreductase [147, 148]. DPI can bind to the heme group of the NOX enzyme and inhibit ROS production. A study in this field showed that DPI administration could inhibit ROS-induced NET formation and extracellular release of NET-derived DNA $[149,150]$.

\section{Other studied NETosis inhibitors}

In this section, other chemical drugs and natural compounds that inhibit NETosis are summarized. It has been reported that low doses of rapamycin and lapatinib can effectively inhibit NET formation, while high doses of these drugs induce NETosis. On the other hand, ponatinib, crizotinib, and bosutinib are identified as NET inducers and can be used in NET-deficient and CGD patients by targeting the NOX downstream intracellular molecules [34]. In contrast, another study showed that bosutinib could inhibit IC-stimulated NET formation but no other type of NETosis, which is receptor-independent and stimulated by the calcium ionophore ionomycin [151]. However, in periodontitis, a combination of bosutinib, ponatinib, and celastrol could reduce phorbol 12-myristate 13-acetate (PMA)-induced ROS production by hyperactive neutrophils, resulting in reducing NET formation $[152,153]$. It appears that the dose of bosutinib, as well as combination with other drugs, can completely change the effect on NETosis and the reason for these discrepancies is probably these cases. Other NET inhibitor compounds such as erlotinib, carmustine, and lapatinib may be employed to treat SLE, CF, and RA as pathologic states in which aberrant NET formation is associated with disease progression [58, 73, 154].

As discussed earlier, ROS production is one of the most important inducers of NETosis, and any compound or substance that can inhibit ROS production, therefore, has the ability to inhibit NET formation by activated neutrophils. In this regard, a study reported that vitamin $\mathrm{C}$ and flavonoids such as catechin hydrate, rutin trihydrate, epicatechin are able to inhibit PMA-induced ROS production. Furthermore, pharmacological substances including 5-aminosalicylic acid (5-ASA) and $\mathrm{N}$-acetyl-L-cysteine (NAC) can inhibit ROS and NET production. Therefore, many antioxidants can increase and decrease pathology by inhibiting the onset of NETosis. However, more studies are needed in this area [155]. Studies show that one of the most important laboratory findings in SLE patients is vitamin D deficiency. Vitamin D as an immunomodulator can modulate the destructive responses of the immune system and prevent autoimmunity. A study has reported that vitamin D can prevent endothelial cell damage by reducing NET formation. As a result, this vitamin can be used as a supplement to treat patients with autoimmune disorders such as SLE [156]. Surprisingly, it has been reported that aerobic exercise recovers lung inflammation in acute lung injury. Moreover, a positive association was observed between inflammatory alveolar macrophage polarization and NET formation. An investigation on LPS-induced acute lung injury mouse models showed that five weeks of aerobic treadmill running could alleviate acute lung injury by inhibiting the NET formation and alveolar macrophages pro-inflammatory phenotype polarization by suppressing ERK1/2 and nuclear factor kappa-light-chain-enhancer of activated B cells (NF- $\mathrm{kB}$ ) signaling pathways [157].

\section{Advantages and disadvantages of NETosis inhibition}

As the fallouts of the reviewed studies showed, NET formation is initially considered a kind of innate immune mechanism against pathogens that can control infections. However, when its production is dysregulated, it can be involved in the pathogenesis of several inflammatory disorders, tumors, and autoimmunity. As a result, inhibition of this phenomenon and its inducing factors can be an effective therapeutic approach to declared diseases. Like various therapeutic tactics, NETosis has its strengths and weaknesses, highlighted in this section.

According to various studies that have been performed so far, inhibition of PAD enzymes, which play a pivotal role in the NET formation, has been very useful. In various diseases, including RA, diabetic wound, multiple sclerosis (MS), colon cancer, atherosclerosis and spinal cord injury models, inhibition of PAD by various factors such as Cl-amidine has had satisfactory outcomes [26, 158-161]. Moreover, inhibition or knock-out of PAD enzymes can reduce the severity of the disease, reduce the citrulline of proteins, especially histones, and reduce inflammation and the production of destructive autoantibodies [162]. On the other hand, inhibition of PAD enzymes is associated with an alteration in differentiation from $\mathrm{T}$ helper (Th) 1 and 
Th17 to Th2, associated with a decrease in inflammatory responses mediated by Th1 and Th17 [163-165]. Investigations on human cancers showed that the inhibition of NETosis could also prevent tumor progression. However, combination therapy with NET inhibitors and checkpoint inhibitors, including anti- cytotoxic T-Lymphocyte associated protein 4 (CTLA4) and programmed death-1 (PD-1) $\mathrm{mAbs}$, can increase the anti-tumor function of $\mathrm{CD} 8^{+} \mathrm{T}$ cells. As a result, NET inhibitors can be used as adjuvants in combination immunotherapies, increasing the effectiveness of immune checkpoint blockers and other anti-cancer agents [166]. In patients with COVID-19, increased inflammation and thrombosis and multiple organ failure have been suggested as important disease features. In this regard, platelets can cause thrombosis by stimulating NETosis, and inhibition of NET in these patients can reduce thrombotic complications [124].

The abnormal and dysregulated NET formation has been reported in several lung diseases [154]. Chronic obstructive pulmonary disease (COPD), characterized by persistent respiratory symptoms and airway limitation due to airway or alveolar abnormalities, is one of these lung diseases [167, 168]. This disorder is most commonly realized in people who have been exposed to toxic gas particles. Evidence suggests that neutrophils are one of the major innate immune cells that infiltrate the lungs and can participate in the pathogenesis of COPD through NET production, inflammation, and direct induction of epithelial and endothelial cell death. As a result, inhibition of NETosis can be considered a suitable target for treating this type of lung disease. Studies showed that the use of recombinant human protease inhibitors and DNase could neutralize and degrade NET-derived DNA and proteins and reduce their destructive effects. Additionally, targeting the 2-chemokine receptor CXC (CXCR2) can inhibit neutrophil trafficking into the lung, reduces inflammation, decreases mucus production, and inhibits lung tissue destruction mediated by neutrophil proteinase [168]. A genetic defect in the cystic fibrosis transmembrane conductance regulator (CFTR) gene causes cystic fibrosis) CF(. Studies in infants with the CFTR mutation showed that peribronchial neutrophil infiltration occurred before the development of lung infection, leading to increased inflammatory response and involvement of the upper and lower airways. Increased mucosal viscosity and small and medium bronchioles obstruction also occurred following those as mentioned earlier infectious and inflammatory responses. Evidence also suggested that neutrophil cytotoxins, NETs, and extracellular DNA are associated with increased mucosal obstruction and lung tissue damage in CF patients.

Furthermore, neutrophil phenotypes, airway $\mathrm{pH}$, and milieu salt concentrations can affect NETotic capacity and neutrophil survival. As a result, attenuation of NETs using different NET inhibitors such as DNAse can manage CF airways inflammation. However, the use of DNAse can lead to the release of cytotoxins from NETs and increase inflammation and even autoimmunity. As a result, further studies are needed to degrade NET residues with the maximum positive effect and minimum release of cytotoxic components [169].

Despite the positive consequences of NET inhibition and its inducing factors such as PAD, MPO, NOX enzymes, as well as inhibition of ROS production in various diseases related to NETosis, it can face some challenges. For example, PAD enzymes are also involved in various biological processes, including protective immunity, regulation of gene expression, and cell differentiation and using PAD inhibitors can impair these biological processes [21]. Studies have shown that PAD-deficient mice are more susceptible to bacterial infections than healthy mice, and this finding suggests that inhibition of PAD and subsequent inhibition of NET may make patients more susceptible to infection [170]. Therefore, the administration of NET inhibitors in immunocompromised patients should be more cautious. Moreover, cyclosporine as an immunosuppressive drug that can inhibit NETosis can disrupt the immune system and the required responses to pathogens clearance, leading to more recurrent infections in under treatment patients $[159,171]$. Another study reported that PAD4 knock-out mice developed systemic inflammation and bacterial keratitis in the local cornea, where neutrophils activate through NETosis to protect against infection [22].

In addition to the antibacterial properties of antibiotics and their use in the management of bacterial infections, these drugs can have an immunomodulatory effect on the properties of immune cells such as neutrophils [172, 173]. In this regard, a study showed that azithromycin and chloramphenicol affect respiratory burst, apoptosis, degranulation of neutrophils as well as NET formation. Their study showed that pre-treatment of neutrophils with chloramphenicol and azithromycin decreased NET formation. Also, among gentamicin and cefotaxime, gentamicin can reduce NET release by neutrophils [173]. As a result, the use of antibiotics with NET formation inhibitory properties can be useful in combination therapies for dysregulated NETosis-mediated inflammatory diseases and management of probable further infection following NET inhibition without interfering with their antimicrobial function [174]. Because effector neutrophils are essential for preserving immune responses to infections, drugs and inhibitors that can selectively and without harm the normal function of neutrophils only inhibit or reduce NET overproduction are preferable to other NET inhibitors. Studies have shown that tetrahydroisoquinolines (THIQs) are a new class of NET formation inhibitors that, unlike the mechanisms as mentioned earlier, do not target the neutrophil granular proteins activity or the formation of ROS and 
only reduce NET formation without weakening neutrophil normal functions [175].

Besides, analyses of transcriptomics disclosed that transcription initiated at multiple loci in all chromosomes prior to the rapid vital type of NETosis than Nox-dependent NETosis. NETosis-specific kinase cascades could activate transcription of different groups of genes in a different manner. Furthermore, transcription inhibitors can suppress vital and Nox-dependent NETosis types without affecting ROS production, essential for antibacterial neutrophil functions [176]. Another of these selective NET inhibitors is an anthracycline, which may reverse transcription initiation and inhibit NETosis. Inhibitory doses of anthracyclines have been shown to suppress ROS production, which is necessary for antimicrobial functions, and do not cause apoptotic cell death in neutrophils. In the case of combination therapy, an anthracycline with dexrazoxane can be used as a heart protective agent and limit the side effects of anthracyclines. Interestingly, dexrazoxane neither affects NETosis nor alters the NET inhibitory ability of anthracyclines. As a result, the correct doses of an anthracycline with dexrazoxane can be used as a highly effective treatment for inhibiting unsolicited NETosis in NET-mediated diseases [177].

On the other hand, some other studies acknowledge that mice and humans with NETosis deficiency who had defects in the MPO or PAD4 enzyme did not differ from healthy groups regarding susceptibility to infection. These findings indicate that using NET inhibitors will not increase the susceptibility to infection in treated patients $[178,179]$. The reason for these discrepancies seems to be the function of the innate immune system in defense against pathogens in a compensatory manner. Because the compensatory mechanisms in cases of inherited or acquired immune response defects could be covered by other components of the immune system [180]. For example, in immunocompromised patients, recurrent infections are not always realized, which can confirm the immune system's network function in defense against pathogens [181].

Although NETs are effectively involved in various infectious diseases and pathogen clearance processes, they can also be destructive due to the release of enzymes and other cytotoxic proteins that cause tissue damage in other inflammatory and autoimmune disorders. Therefore, control and management of NET overproduction are quickly becoming a potential target for treatment, but it is important to note that different NET inhibitors may have other side effects, such as weakened immune systems and increased susceptibility to infections. Moreover, it is possible that optimizing the effectiveness and clinical outcomes of treatment and managing NETs may require the use of combination therapies with minimum impacts on weakening the immune system [174].

\section{Concluding remarks}

Based on the findings of recent studies on the role of NETosis in the host defense and innate immunity as well as the pathogenesis of various diseases, it appears that dysregulated NETosis can release a variety of intracellular genes out of the cell. Defects in the clearance and degradation of NET debris cause recognition by the immune system, failure of tolerance to local antigens, and activation of autoreactive immune cells, whose destructive responses cause tissue damage in autoimmune diseases. On the other hand, the use of NET inhibitors can effectively treat several NET-associated diseases, although this type of treatment should be accompanied by monitoring patients for control of recurrent infections, especially in immunocompromised patients. Therefore, NET inhibitor drug formulations or enzymes involved with minimal side effects can be useful in treating various NET-associated diseases. Further study and understanding of the regulation and balance of NET induction, inhibition, and degradation using NET inhibitors will be necessary without compromising the patient's immune defenses. In order to apply this type of treatment in the clinic, further investigations are needed to accurately understand the functions and effects of NETs on health and disease regarding the heterogeneous patterns of disease [182].

Author contributions TMC: Conceptualization, Writing-Original draft preparation, data collection. SA: Supervision, Writing-Reviewing and Editing.

Data availability Not applicable.

Code availability Not applicable.

\section{Declarations}

Conflict of interest All authors of this article declare that they have no conflict of interest.

Ethical approval Not applicable.

Consent to participate Not applicable.

Consent for publication Not applicable.

\section{References}

1. Brinkmann V, Reichard U, Goosmann C, Fauler B, Uhlemann Y, Weiss DS, Weinrauch Y, Zychlinsky A (2004) Neutrophil extracellular traps kill bacteria. Science 303(5663):1532-1535

2. Papayannopoulos V (2018) Neutrophil extracellular traps in immunity and disease. Nat Rev Immunol 18(2):134-147 
3. Brinkmann V (2018) Neutrophil extracellular traps in the second decade. J Innate Immun 10(5-6):414-421

4. Berger-Achituv S, Brinkmann V, Abu-Abed U, Kühn LI, BenEzra J, Elhasid R, Zychlinsky A (2013) A proposed role for neutrophil extracellular traps in cancer immunoediting. Front Immunol 4:48

5. Dąbrowska D, Jabłońska E, Garley M, Ratajczak-Wrona W, Iwaniuk A (2016) New aspects of the biology of neutrophil extracellular traps. Scand J Immunol 84(6):317-322

6. Masucci MT, Minopoli M, Del Vecchio S, Carriero MV (2020) The emerging role of neutrophil extracellular traps (NETs) in tumor progression and metastasis. Front Immunol. https://doi. org/10.3389/fimmu.2020.01749

7. Nakazawa D, Shida H, Tomaru U, Yoshida M, Nishio S, Atsumi T, Ishizu A (2014) Enhanced formation and disordered regulation of NETs in myeloperoxidase-ANCA-associated microscopic polyangiitis. J Am Soc Nephrol 25(5):990-997

8. Warnatsch A, Ioannou M, Wang Q, Papayannopoulos V (2015) Neutrophil extracellular traps license macrophages for cytokine production in atherosclerosis. Science 349(6245):316-320

9. Fuchs TA, Brill A, Duerschmied D, Schatzberg D, Monestier M, Myers DD, Wrobleski SK, Wakefield TW, Hartwig JH, Wagner DD (2010) Extracellular DNA traps promote thrombosis. Proc Natl Acad Sci 107(36):15880-15885

10. White P, Chicca I, Cooper P, Milward M, Chapple I (2016) Neutrophil extracellular traps in periodontitis: a web of intrigue. $\mathrm{J}$ Dent Res 95(1):26-34

11. Vitkov L, Hartl D, Minnich B, Hannig M (2017) Janus-faced neutrophil extracellular traps in periodontitis. Front Immunol 8:1404

12. Fresneda Alarcon M, McLaren Z, Wright HL (2021) Neutrophils in the pathogenesis of rheumatoid arthritis and systemic lupus erythematosus: same foe different MO. Front Immunol 12:570

13. Németh T, Sperandio M, Mócsai A (2020) Neutrophils as emerging therapeutic targets. Nat Rev Drug Discovery 19(4):253-275

14. Yang C-T, Chen L, Chen W-L, Li N, Chen M-J, Li X, Zheng X, Zhao Y-Z, Wu Y-X, Xian M (2019) Hydrogen sulfide primes diabetic wound to close through inhibition of NETosis. Mol Cell Endocrinol 480:74-82

15. Kraaij T, Kamerling SW, de Rooij EN, van Daele PL, Bredewold OW, Bakker JA, Bajema IM, Scherer HU, Toes RE, Huizinga TJ (2018) The NET-effect of combining rituximab with belimumab in severe systemic lupus erythematosus. J Autoimmun 91:45-54

16. Zhang S, Zhang Q, Wang F, Guo X, Liu T, Zhao Y, Gu B, Chen $\mathrm{H}, \mathrm{Li}$ Y (2020) Hydroxychloroquine inhibiting neutrophil extracellular trap formation alleviates hepatic ischemia/reperfusion injury by blocking TLR9 in mice. Clin Immunol 216:108461

17. Zheng W, Warner R, Ruggeri R, Su C, Cortes C, Skoura A, Ward J, Ahn K, Kalgutkar A, Sun D (2015) PF-1355, a mechanismbased myeloperoxidase inhibitor, prevents immune complex vasculitis and anti-glomerular basement membrane glomerulonephritis. J Pharmacol Exp Ther 353(2):288-298

18. Stockley R, De Soyza A, Gunawardena K, Perrett J, ForsmanSemb K, Entwistle N, Snell N (2013) Phase II study of a neutrophil elastase inhibitor (AZD9668) in patients with bronchiectasis. Respir Med 107(4):524-533

19. van Dam LS, Osmani Z, Kamerling SW, Kraaij T, Bakker JA, Scherer HU, Rabelink TJ, Voll RE, Alexander T, Isenberg DA (2020) A reverse translational study on the effect of rituximab, rituximab plus belimumab, or bortezomib on the humoral autoimmune response in SLE. Rheumatology 59(10):2734-2745

20 Teo CY, Shave S, Chor ALT, Salleh AB, Rahman MBBA, Walkinshaw MD, Tejo BA (2012) Discovery of a new class of inhibitors for the protein arginine deiminase type 4 (PAD4) by structure-based virtual screening. BMC Bioinform. https://doi. org/10.1186/1471-2105-13-S17-S4
21. Curran AM, Naik P, Giles JT, Darrah E (2020) PAD enzymes in rheumatoid arthritis: pathogenic effectors and autoimmune targets. Nat Rev Rheumatol 16(6):301-315

22. Thanabalasuriar A, Scott BNV, Peiseler M, Willson ME, Zeng Z, Warrener P, Keller AE, Surewaard BGJ, Dozier EA, Korhonen JT (2019) Neutrophil extracellular traps confine Pseudomonas aeruginosa ocular biofilms and restrict brain invasion. Cell Host Microb 25(4):526-536

23. Grayson PC, Kaplan MJ (2016) At the bench: neutrophil extracellular traps (NETs) highlight novel aspects of innate immune system involvement in autoimmune diseases. J Leukoc Biol 99(2):253-264

24. Remijsen Q, Kuijpers T, Wirawan E, Lippens S, Vandenabeele P, Berghe TV (2011) Dying for a cause: NETosis, mechanisms behind an antimicrobial cell death modality. Cell Death Differ 18(4):581-588

25. Saffarzadeh M (2018) Neutrophil extracellular traps as a drug target to counteract chronic and acute inflammation. Curr Pharm Biotechnol 19(15):1196-1202

26. Fadini GP, Menegazzo L, Rigato M, Scattolini V, Poncina N, Bruttocao A, Ciciliot S, Mammano F, Ciubotaru CD, Brocco E (2016) NETosis delays diabetic wound healing in mice and humans. Diabetes 65(4):1061-1071

27. Metzler KD, Goosmann C, Lubojemska A, Zychlinsky A, Papayannopoulos V (2014) A myeloperoxidase-containing complex regulates neutrophil elastase release and actin dynamics during NETosis. Cell Rep 8(3):883-896

28. de Bont CM, Boelens WC, Pruijn GJ (2019) NETosis, complement, and coagulation: a triangular relationship. Cell Mol Immunol 16(1):19-27

29. Pires RH, Felix SB, Delcea M (2016) The architecture of neutrophil extracellular traps investigated by atomic force microscopy. Nanoscale 8(29):14193-14202

30. Urban CF, Reichard U, Brinkmann V, Zychlinsky A (2006) Neutrophil extracellular traps capture and kill Candida albicans yeast and hyphal forms. Cell Microbiol 8(4):668-676

31. Wang Y, Li M, Stadler S, Correll S, Li P, Wang D, Hayama R, Leonelli L, Han H, Grigoryev SA (2009) Histone hypercitrullination mediates chromatin decondensation and neutrophil extracellular trap formation. J Cell Biol 184(2):205-213

32. Sørensen OE, Borregaard N (2016) Neutrophil extracellular traps-the dark side of neutrophils. J Clin Investig 126(5):1612-1620

33. Lin AM, Rubin CJ, Khandpur R, Wang JY, Riblett M, Yalavarthi S, Villanueva EC, Shah P, Kaplan MJ, Bruce AT (2011) Mast cells and neutrophils release IL-17 through extracellular trap formation in psoriasis. J Immunol 187(1):490-500

34. Fuchs TA, Abed U, Goosmann C, Hurwitz R, Schulze I, Wahn V, Weinrauch Y, Brinkmann V, Zychlinsky A (2007) Novel cell death program leads to neutrophil extracellular traps. J Cell Biol 176(2):231-241

35. Martinez-Prat L, Lucia D, Ibarra C, Mahler M, Dervieux T (2019) Antibodies targeting protein-arginine deiminase 4 (PAD4) demonstrate diagnostic value in rheumatoid arthritis. Ann Rheum Dis 78(3):434-436

36. Neeli I, Khan SN, Radic M (2008) Histone deimination as a response to inflammatory stimuli in neutrophils. J Immunol 180(3):1895-1902

37. Liu CL, Tangsombatvisit S, Rosenberg JM, Mandelbaum G, Gillespie EC, Gozani OP, Alizadeh AA, Utz PJ (2012) Specific post-translational histone modifications of neutrophil extracellular traps as immunogens and potential targets of lupus autoantibodies. Arthritis Res Ther 14(1):1-14

38. Brinkmann V, Zychlinsky A (2012) Neutrophil extracellular traps: is immunity the second function of chromatin? J Cell Biol 198(5):773-783 
39 Varjú I, Kolev K (2014) Fibrinolysis at the interface of thrombosis and inflammation-the role of neutrophil extracellular traps. Fibrinolysis and thrombolysis. InTech, London

40. Douda DN, Khan MA, Grasemann H, Palaniyar N (2015) SK3 channel and mitochondrial ROS mediate NADPH oxidaseindependent NETosis induced by calcium influx. Proc Natl Acad Sci 112(9):2817-2822

41. Yipp BG, Petri B, Salina D, Jenne CN, Scott BN, Zbytnuik LD, Pittman K, Asaduzzaman M, Wu K, Meijndert HC (2012) Infection-induced NETosis is a dynamic process involving neutrophil multitasking in vivo. Nat Med 18(9):1386-1393

42. Pilsczek FH, Salina D, Poon KK, Fahey C, Yipp BG, Sibley CD, Robbins SM, Green FH, Surette MG, Sugai M (2010) A novel mechanism of rapid nuclear neutrophil extracellular trap formation in response to Staphylococcus aureus. J Immunol 185(12):7413-7425

43. Rohrbach A, Slade D, Thompson P, Mowen K (2012) Activation of PAD4 in NET formation. Front Immunol 3(360):2012

44 Mesa MA, Vasquez G (2013) NETosis. Autoimmun Dis 2013:1-7

45. Doster RS, Rogers LM, Gaddy JA, Aronoff DM (2018) Macrophage extracellular traps: a scoping review. J Innate Immun 10(1):3-13

46. Mahajan A, Herrmann M, Muñoz LE (2016) Clearance deficiency and cell death pathways: a model for the pathogenesis of SLE. Front Immunol 7:35

47. Farrera C, Fadeel B (2013) Macrophage clearance of neutrophil extracellular traps is a silent process. J Immunol 191(5):2647-2656

48. Jiménez-Alcázar M, Rangaswamy C, Panda R, Bitterling J, Simsek YJ, Long AT, Bilyy R, Krenn V, Renné C, Renné T (2017) Host DNases prevent vascular occlusion by neutrophil extracellular traps. Science 358(6367):1202-1206

49. Kessenbrock K, Krumbholz M, Schönermarck U, Back W, Gross WL, Werb Z, Gröne H-J, Brinkmann V, Jenne DE (2009) Netting neutrophils in autoimmune small-vessel vasculitis. Nat Med 15(6):623-625

50. Pinegin B, Vorobjeva N, Pinegin V (2015) Neutrophil extracellular traps and their role in the development of chronic inflammation and autoimmunity. Autoimmun Rev 14(7):633-640

51. Li RH, Johnson LR, Kohen C, Tablin F (2018) A novel approach to identifying and quantifying neutrophil extracellular trap formation in septic dogs using immunofluorescence microscopy. BMC Vet Res 14(1):1-7

52. Li RH, Tablin F (2018) A comparative review of neutrophil extracellular traps in sepsis. Front Vet Sci 5:291

53. Ekaney ML, Otto GP, Sossdorf M, Sponholz C, Boehringer M, Loesche W, Rittirsch D, Wilharm A, Kurzai O, Bauer M (2014) Impact of plasma histones in human sepsis and their contribution to cellular injury and inflammation. Crit Care 18(5):1-9

54. Akgul C, Moulding DA, Edwards SW (2001) Molecular control of neutrophil apoptosis. FEBS Lett 487(3):318-322

55. Xu J, Zhang X, Pelayo R, Monestier M, Ammollo CT, Semeraro F, Taylor FB, Esmon NL, Lupu F, Esmon CT (2009) Extracellular histones are major mediators of death in sepsis. Nat Med 15(11):1318-1321

56. Abrams ST, Zhang N, Manson J, Liu T, Dart C, Baluwa F, Wang SS, Brohi K, Kipar A, Yu W (2013) Circulating histones are mediators of trauma-associated lung injury. Am J Respir Crit Care Med 187(2):160-169

57. Pieterse E, Rother N, Yanginlar C, Gerretsen J, Boeltz S, Munoz LE, Herrmann M, Pickkers P, Hilbrands LB, van der Vlag J (2018) Cleaved N-terminal histone tails distinguish between NADPH oxidase (NOX)-dependent and NOX-independent pathways of neutrophil extracellular trap formation. Ann Rheum Dis 77(12): 1790-1798

58. Hakkim A, Fürnrohr BG, Amann K, Laube B, Abed UA, Brinkmann V, Herrmann M, Voll RE, Zychlinsky A (2010) Impairment of neutrophil extracellular trap degradation is associated with lupus nephritis. Proc Natl Acad Sci 107(21):9813-9818

59. Kaplan MJ (2011) Neutrophils in the pathogenesis and manifestations of SLE. Nat Rev Rheumatol 7(12):691-699

60. Villanueva E, Yalavarthi S, Berthier CC, Hodgin JB, Khandpur R, Lin AM, Rubin CJ, Zhao W, Olsen SH, Klinker M (2011) Netting neutrophils induce endothelial damage, infiltrate tissues, and expose immunostimulatory molecules in systemic lupus erythematosus. J Immunol 187(1):538-552

61. Lande R, Ganguly D, Facchinetti V, Frasca L, Conrad C, Gregorio J, Meller S, Chamilos G, Sebasigari R, Riccieri V (2011) Neutrophils activate plasmacytoid dendritic cells by releasing self-DNA-peptide complexes in systemic lupus erythematosus. Sci Transl Med 3(73):73ra19-73ra19

62. Dieker J, Berden JH, Bakker M, Briand J-P, Muller S, Voll R, Sjöwall C, Herrmann M, Hilbrands LB, van der Vlag J (2016) Autoantibodies against modified histone peptides in SLE patients are associated with disease activity and lupus nephritis. PLoS One 11(10):e0165373

63. Safi R, Al-Hage J, Abbas O, Kibbi AG, Nassar D (2019) Investigating the presence of neutrophil extracellular traps in cutaneous lesions of different subtypes of lupus erythematosus. Exp Dermatol 28(11):1348-1352

64 Sherer Y, Gorstein A, Fritzler MJ, Shoenfeld Y (2004) Autoantibody explosion in systemic lupus erythematosus: more than 100 different antibodies found in SLE patients. Seminars in arthritis and rheumatism. Elsevier, Amsterdam, pp 501-537

65. Gripenberg M, Helve T, Kurki P (1985) Profiles of antibodies to histones, DNA and IgG in patients with systemic rheumatic diseases determined by ELISA. J Rheumatol 12(5):934-939

66. Chapman EA, Lyon M, Simpson D, Mason D, Beynon RJ, Moots RJ, Wright HL (2019) Caught in a trap? Proteomic analysis of neutrophil extracellular traps in rheumatoid arthritis and systemic lupus erythematosus. Front Immunol 10:423

67. Carmona-Rivera C, Zhao W, Yalavarthi S, Kaplan MJ (2015) Neutrophil extracellular traps induce endothelial dysfunction in systemic lupus erythematosus through the activation of matrix metalloproteinase-2. Ann Rheum Dis 74(7):1417-1424

68. Pieterse E, Rother N, Garsen M, Hofstra JM, Satchell SC, Hoffmann M, Loeven MA, Knaapen HK, van der Heijden OW, Berden JH (2017) Neutrophil extracellular traps drive endothelial-to-mesenchymal transition. Arterioscler Thromb Vasc Biol 37(7):1371-1379

69. Bruschi M, Sinico RA, Moroni G, Pratesi F, Migliorini P, Galetti M, Murtas C, Tincani A, Madaio M, Radice A (2014) Glomerular autoimmune multicomponents of human lupus nephritis in vivo: $\alpha$-enolase and annexin AI. J Am Soc Nephrol 25(11):2483-2498

70. Mayadas TN, Rosetti F, Ernandez T, Sethi S (2010) Neutrophils: game changers in glomerulonephritis? Trends Mol Med 16(8):368-378

71. Nowling TK, Gilkeson GS (2011) Mechanisms of tissue injury in lupus nephritis. Arthritis Res Ther 13(6):1-9

72. Birkelund S, Bennike TB, Kastaniegaard K, Lausen M, Poulsen TBG, Kragstrup TW, Deleuran BW, Christiansen G, Stensballe A (2020) Proteomic analysis of synovial fluid from rheumatic arthritis and spondyloarthritis patients. Clin Proteomics 17(1):1-15

73. Khandpur R, Carmona-Rivera C, Vivekanandan-Giri A, Gizinski A, Yalavarthi S, Knight JS, Friday S, Li S, Patel RM, Subramanian V (2013) NETs are a source of citrullinated autoantigens 
and stimulate inflammatory responses in rheumatoid arthritis. Sci Transl Med 5(178):178ra40-178ra40

74. Spengler J, Lugonja B, Jimmy Ytterberg A, Zubarev RA, Creese AJ, Pearson MJ, Grant MM, Milward M, Lundberg K, Buckley CD (2015) Release of active peptidyl arginine deiminases by neutrophils can explain production of extracellular citrullinated autoantigens in rheumatoid arthritis synovial fluid. Arthr Rheumatol 67(12):3135-3145

75. Kinloch A, Lundberg K, Wait R, Wegner N, Lim NH, Zendman AJ, Saxne T, Malmstr V, Venables PJ (2008) Synovial fluid is a site of citrullination of autoantigens in inflammatory arthritis. Arthr Rheum Off J Am Coll Rheumatol 58(8):2287-2295

76. Kinloch A, Tatzer V, Wait R, Peston D, Lundberg K, Donatien P, Moyes D, Taylor PC, Venables PJ (2005) Identification of citrullinated $\alpha$-enolase as a candidate autoantigen in rheumatoid arthritis. Arthr Res Ther 7(6):1-9

77. Carmona-Rivera C, Carlucci PM, Moore E, Lingampalli N, Uchtenhagen H, James E, Liu Y, Bicker KL, Wahamaa H, Hoffmann V (2017) Synovial fibroblast-neutrophil interactions promote pathogenic adaptive immunity in rheumatoid arthritis. Sci Immunol. https://doi.org/10.1126/sciimmunol.aag3358

78. Carmona-Rivera C, Carlucci PM, Goel RR, James E, Brooks SR, Rims C, Hoffmann V, Fox DA, Buckner JH, Kaplan MJ (2020) Neutrophil extracellular traps mediate articular cartilage damage and enhance cartilage component immunogenicity in rheumatoid arthritis. JCI Insight. https://doi.org/10.1172/jci.insight. 139388

79. Mattey DL, Nixon NB, Dawes PT (2012) Association of circulating levels of MMP-8 with mortality from respiratory disease in patients with rheumatoid arthritis. Arthr Res Ther 14(5):1-9

80. Itoh T, Matsuda H, Tanioka M, Kuwabara K, Itohara S, Suzuki $\mathrm{R}$ (2002) The role of matrix metalloproteinase-2 and matrix metalloproteinase-9 in antibody-induced arthritis. J Immunol 169(5):2643-2647

81. Corsiero E, Bombardieri M, Carlotti E, Pratesi F, Robinson W, Migliorini P, Pitzalis C (2016) Single cell cloning and recombinant monoclonal antibodies generation from RA synovial B cells reveal frequent targeting of citrullinated histones of NETs. Ann Rheum Dis 75(10): 1866-1875

82. Gonzalez-Aparicio M, Alfaro C (2019) Influence of interleukin-8 and neutrophil extracellular trap (NET) formation in the tumor microenvironment: is there a pathogenic role? J Immunol Res. https://doi.org/10.1155/2019/6252138

83. Snoderly HT, Boone BA, Bennewitz MF (2019) Neutrophil extracellular traps in breast cancer and beyond: current perspectives on NET stimuli, thrombosis and metastasis, and clinical utility for diagnosis and treatment. Breast Cancer Res 21(1):1-13

84. Homa-Mlak I, Majdan A, Mlak R, Małecka-Massalska T (2016) Metastatic potential of NET in neoplastic disease. Postepy Hig Med Dosw(Online) 70:887-895

85. Park J, Wysocki RW, Amoozgar Z, Maiorino L, Fein MR, Jorns J, Schott AF, Kinugasa-Katayama Y, Lee Y, Won NH (2016) Cancer cells induce metastasis-supporting neutrophil extracellular DNA traps. Sci Transl Med 8(361):361ra138-361ra138

86. Gupta AK, Joshi MB, Philippova M, Erne P, Hasler P, Hahn S, Resink TJ (2010) Activated endothelial cells induce neutrophil extracellular traps and are susceptible to NETosis-mediated cell death. FEBS Lett 584(14):3193-3197

87. Demers M, Krause DS, Schatzberg D, Martinod K, Voorhees JR, Fuchs TA, Scadden DT, Wagner DD (2012) Cancers predispose neutrophils to release extracellular DNA traps that contribute to cancer-associated thrombosis. Proc Natl Acad Sci 109(32):13076-13081

88. Avalos BR, Gasson JC, Hedvat C, Quan SG, Baldwin GC, Weisbart RH, Williams RE, Golde DW, DiPersio JF (1990) Human granulocyte colony-stimulating factor: biologic activities and receptor characterization on hematopoietic cells and small cell lung cancer cell lines

89. Abdol Razak N, Elaskalani O, Metharom P (2017) Pancreatic cancer-induced neutrophil extracellular traps: a potential contributor to cancer-associated thrombosis. Int J Mol Sci 18(3):487

90 Ling S, Xu J-W (2021) NETosis as a pathogenic factor for heart failure. Oxidative Med Cell Longev 2021:1-24

91. Ge L, Zhou X, Ji W-J, Lu R-Y, Zhang Y, Zhang Y-D, Ma Y-Q, Zhao J-H, Li Y-M (2015) Neutrophil extracellular traps in ischemia-reperfusion injury-induced myocardial no-reflow: therapeutic potential of DNase-based reperfusion strategy. Am J Physiol-Heart Circ Physiol 308(5):H500-H509

92. Mangold A, Alias S, Scherz T, Hofbauer TM, Jakowitsch J, Panzenböck A, Simon D, Laimer D, Bangert C, Kammerlander A (2015) Coronary neutrophil extracellular trap burden and deoxyribonuclease activity in ST-elevation acute coronary syndrome are predictors of ST-segment resolution and infarct size. Circ Res 116(7):1182-1192

93. Hofbauer TM, Mangold A, Scherz T, Seidl V, Panzenböck A, Ondracek AS, Müller J, Schneider M, Binder T, Hell L (2019) Neutrophil extracellular traps and fibrocytes in ST-segment elevation myocardial infarction. Basic Res Cardiol 114(5):1-15

94. Berkovitch A, Younis A, Grossman Y, Segev S, Kivity S, Sidi Y, Beinart R, Goldenberg I, Maor E (2019) Relation of neutrophil to lymphocyte ratio to risk of incident atrial fibrillation. Am J Cardiol 123(3):396-401

95. Gibson PH, Cuthbertson BH, Croal BL, Rae D, El-Shafei H, Gibson G, Jeffrey RR, Buchan KG, Hillis GS (2010) Usefulness of neutrophil/lymphocyte ratio as predictor of new-onset atrial fibrillation after coronary artery bypass grafting. Am J Cardiol 105(2):186-191

96. Friedrichs K, Adam M, Remane L, Mollenhauer M, Rudolph V, Rudolph TK, Andrié RP, Stöckigt F, Schrickel JW, Ravekes $\mathrm{T}$ (2014) Induction of atrial fibrillation by neutrophils critically depends on CD11b/CD18 integrins. PloS one 9(2):e89307

97. Rudolph V, Andrie RP, Rudolph TK, Friedrichs K, Klinke A, Hirsch-Hoffmann B, Schwoerer AP, Lau D, Fu X, Klingel K (2010) Myeloperoxidase acts as a profibrotic mediator of atrial fibrillation. Nat Med 16(4):470-474

98. Wang Y, Sano S, Oshima K, Sano M, Watanabe Y, Katanasaka Y, Yura Y, Jung C, Anzai A, Swirski FK (2019) Wnt5a-mediated neutrophil recruitment has an obligatory role in pressure overload-induced cardiac dysfunction. Circulation 140(6):487-499

99. Mozzini C, Garbin U, Pasini AMF, Cominacini L (2017) An exploratory look at NETosis in atherosclerosis. Intern Emerg Med 12(1):13-22

100. Qi H, Yang S, Zhang L (2017) Neutrophil extracellular traps and endothelial dysfunction in atherosclerosis and thrombosis. Front Immunol 8:928

101. Franck G, Mawson TL, Folco EJ, Molinaro R, Ruvkun V, Engelbertsen D, Liu X, Tesmenitsky Y, Shvartz E, Sukhova GK (2018) Roles of PAD4 and NETosis in experimental atherosclerosis and arterial injury: implications for superficial erosion. Circ Res 123(1):33-42

102. Njeim R, Azar WS, Fares AH, Azar ST, Kassouf HK, Eid AA (2020) NETosis contributes to the pathogenesis of diabetes and its complications. J Mol Endocrinol 65(4):R65-R76

103. Rajendran V, Uppoor A (2018) A perspective on NETosis in diabetes and periodontal diseases. J Indian Soc Periodontol 22(4):290

104. Saffarzadeh M, Juenemann C, Queisser MA, Lochnit G, Barreto G, Galuska SP, Lohmeyer J, Preissner KT (2012) Neutrophil extracellular traps directly induce epithelial and endothelial cell death: a predominant role of histones. PloS One 7(2):e32366

105. Looney MR, Nguyen JX, Hu Y, Van Ziffle JA, Lowell CA, Matthay MA (2009) Platelet depletion and aspirin treatment protect 
mice in a two-event model of transfusion-related acute lung injury. J Clin Investig 119(11):3450-3461

106. Haldar P, Pavord ID (2007) Noneosinophilic asthma: a distinct clinical and pathologic phenotype. J Allergy Clin Immunol 119(5):1043-1052

107. Shannon J, Ernst P, Yamauchi Y, Olivenstein R, Lemiere C, Foley S, Cicora L, Ludwig M, Hamid Q, Martin JG (2008) Differences in airway cytokine profile in severe asthma compared to moderate asthma. Chest 133(2):420-426

108. Lionetti V, Lisi A, Patrucco E, De Giuli P, Milazzo MG, Ceci S, Wymann M, Lena A, Gremigni V, Fanelli V (2006) Lack of phosphoinositide 3-kinase- $\gamma$ attenuates ventilator-induced lung injury. Crit Care Med 34(1):134-141

109. Yang W, Tao Y, Wu Y, Zhao X, Ye W, Zhao D, Fu L, Tian C, Yang J, He F (2019) Neutrophils promote the development of reparative macrophages mediated by ROS to orchestrate liver repair. Nat Commun 10(1):1-14

110. Kumar KP, Nicholls AJ, Wong CH (2018) Partners in crime: neutrophils and monocytes/macrophages in inflammation and disease. Cell Tissue Res 371(3):551-565

111. Sadatomo A, Inoue Y, Ito H, Karasawa T, Kimura H, Watanabe S, Mizushina Y, Nakamura J, Kamata R, Kasahara T (2017) Interaction of neutrophils with macrophages promotes IL-1 $\beta$ maturation and contributes to hepatic ischemia-reperfusion injury. J Immunol 199(9):3306-3315

112. Aktas G, Duman T, Atak B, Kurtkulagi O, Bilgin S, Basaran E, Demirkol M, Kosekli M (2020) Irritable bowel syndrome is associated with novel inflammatory markers derived from hemogram parameters. Family Med Prim Care Rev 22(2):107-110

113. Li H, Li Y, Song C, Hu Y, Dai M, Liu B, Pan P (2021) Neutrophil extracellular traps augmented alveolar macrophage pyroptosis via AIM2 inflammasome activation in LPS-induced ALI/ARDS. J Inflamm Res 14:4839

114. Hanff TC, Mohareb AM, Giri J, Cohen JB, Chirinos JA (2020) Thrombosis in COVID-19. Am J Hematol 95(12):1578-1589

115. Tomar B, Anders H-J, Desai J, Mulay SR (2020) Neutrophils and neutrophil extracellular traps drive necroinflammation in COVID-19. Cells 9(6):1383

116. Gremese E, Ferraccioli G (2021) The pathogenesis of microthrombi in COVID-19 cannot be controlled by DOAC: NETosis should be the target. J Intern Med 289(3):420

117. Zuo Y, Yalavarthi S, Shi H, Gockman K, Zuo M, Madison JA, Blair C, Weber A, Barnes BJ, Egeblad M (2020) Neutrophil extracellular traps in COVID-19. JCI Insight. https://doi.org/10. 1172/jci.insight. 138999

118. Sinha N, Balayla G (2020) Hydroxychloroquine and covid-19. Postgrad Med J 96(1139):550-555

119. Ponticelli C, Moroni G (2017) Hydroxychloroquine in systemic lupus erythematosus (SLE). Expert Opin Drug Saf 16(3):411-419

120. Kyburz D, Brentano F, Gay S (2006) Mode of action of hydroxychloroquine in RA - evidence of an inhibitory effect on toll-like receptor signaling. Nat Clin Pract Rheumatol 2(9):458-459

121 Hahn S, Giaglis S, Chowdury CS, Hösli I, Hasler P (2013) Modulation of neutrophil NETosis: interplay between infectious agents and underlying host physiology. Semin Immunopathol 35:439-453

122. Mazetto BM, Hounkpe BW, Saraiva S, Bizzacchi JMA, De Paula EV, Orsi FA (2018) Hydroxychloroquine therapy and netosis regulators expression in patients with primary antiphospholipid syndrome. Blood 132:5049

123. Skendros P, Mitroulis I, Ritis K (2018) Autophagy in neutrophils: from granulopoiesis to neutrophil extracellular traps. Front Cell Dev Biol 6:109

124. Skendros P, Mitsios A, Chrysanthopoulou A, Mastellos DC, Metallidis S, Rafailidis P, Ntinopoulou M, Sertaridou E,
Tsironidou V, Tsigalou C (2020) Complement and tissue factorenriched neutrophil extracellular traps are key drivers in COVID19 immunothrombosis. J Clin Investig 130(11):6151-6157

125. Jung H, Bobba R, Su J, Shariati-Sarabi Z, Gladman DD, Urowitz M, Lou W, Fortin PR (2010) The protective effect of antimalarial drugs on thrombovascular events in systemic lupus erythematosus. Arthr Rheum 62(3):863-868

126. Solomon DH, Glynn RJ, Karlson EW, Lu F, Corrigan C, Colls J, Xu C, MacFadyen J, Barbhaiya M, Berliner N (2020) Adverse effects of low-dose methotrexate: a randomized trial. Ann Intern Med 172(6):369-380

127. Laurindo I, Mello S, Cossermelli W (1995) Influence of low doses of methotrexate on superoxide anion production by polymorphonuclear leukocytes from patients with rheumatoid arthritis. J Rheumatol 22(4):633-638

128. Sperling RI, Benincaso AI, Anderson RJ, Coblyn JS, Austen KF, Weinblatt ME (1992) Acute and chronic suppression of leukotriene B4 synthesis ex vivo in neutrophils from patients with rheumatoid arthritis beginning treatment with methotrexate. Arthr Rheum Off J Am Coll Rheumatol 35(4):376-384

129. Weinmann P, Moura R, Caetano-Lopes J, Pereira P, Canhao H, Queiroz M, Fonseca J (2007) Delayed neutrophil apoptosis in very early rheumatoid arthritis patients is abrogated by methotrexate therapy. Clin Exp Rheumatol 25(6):885

130. Schälter F, Dürholz K, Bucci L, Burmester G, Caporali R, Figuereido C, Cobra JF, Manger B, Zaiss MM, Schett G (2021) Does methotrexate influence COVID-19 infection? Case series and mechanistic data. Arthr Res Ther 23(1):1-6

131. Friebe D, Yang T, Schmidt T, Borg N, Steckel B, Ding Z, Schrader J (2014) Purinergic signaling on leukocytes infiltrating the LPS-injured lung. PLoS One 9(4):e95382

132. Ali RA, Gandhi AA, Meng H, Yalavarthi S, Vreede AP, Estes SK, Palmer OR, Bockenstedt PL, Pinsky DJ, Greve JM (2019) Adenosine receptor agonism protects against NETosis and thrombosis in antiphospholipid syndrome. Nat Commun $10(1): 1-12$

133. Wright HL, Moots RJ, Bucknall RC, Edwards SW (2010) Neutrophil function in inflammation and inflammatory diseases. Rheumatology 49(9):1618-1631

134. Long F, Wang Y-X, Liu L, Zhou J, Cui R-Y, Jiang C-L (2005) Rapid nongenomic inhibitory effects of glucocorticoids on phagocytosis and superoxide anion production by macrophages. Steroids 70(1):55-61

135. Stevens T, Ekholm K, Gränse M, Lindahl M, Kozma V, Jungar C, Ottosson T, Falk-Håkansson H, Churg A, Wright JL (2011) AZD9668: pharmacological characterization of a novel oral inhibitor of neutrophil elastase. J Pharmacol Exp Ther 339(1):313-320

136. Li M, Lin C, Deng H, Strnad J, Bernabei L, Vogl DT, Burke JJ, Nefedova Y (2020) A novel peptidylarginine deiminase 4 (PAD4) inhibitor BMS-P5 blocks formation of neutrophil extracellular traps and delays progression of multiple myeloma. Mol Cancer Ther 19(7):1530-1538

137. Lewis HD, Liddle J, Coote JE, Atkinson SJ, Barker MD, Bax BD, Bicker KL, Bingham RP, Campbell M, Chen YH (2015) Inhibition of PAD4 activity is sufficient to disrupt mouse and human NET formation. Nat Chem Biol 11(3):189-191

138. Baker KP, Edwards BM, Main SH, Choi GH, Wager RE, Halpern WG, Lappin PB, Riccobene T, Abramian D, Sekut L (2003) Generation and characterization of LymphoStat-B, a human monoclonal antibody that antagonizes the bioactivities of $\mathrm{B}$ lymphocyte stimulator. Arthr Rheum 48(11):3253-3265

139 Maloney DG, Smith B, Rose A (2002) Rituximab: mechanism of action and resistance. Semin Oncol 29:2-9

140. Halpern WG, Lappin P, Zanardi T, Cai W, Corcoran M, Zhong J, Baker KP (2006) Chronic administration of belimumab, a BLyS 
antagonist, decreases tissue and peripheral blood B-lymphocyte populations in cynomolgus monkeys: pharmacokinetic, pharmacodynamic, and toxicologic effects. Toxicol Sci 91(2):586-599

141. Rosas IO, Bräu N, Waters M, Go RC, Hunter BD, Bhagani S, Skiest D, Aziz MS, Cooper N, Douglas IS (2021) Tocilizumab in hospitalized patients with severe Covid-19 pneumonia. N Engl J Med 384(16):1503-1516

142. Shetty A, Hanson R, Korsten P, Shawagfeh M, Arami S, Volkov S, Vila O, Swedler W, Shunaigat AN, Smadi S (2014) Tocilizumab in the treatment of rheumatoid arthritis and beyond. Drug Des Dev Ther 8:349

143. Ocampo V, Haaland D, Legault K, Mittoo S, Aitken E (2016) Successful treatment of recurrent pleural and pericardial effusions with tocilizumab in a patient with systemic lupus erythematous. Case Rep 2016:bcr2016215423

144. Alraouji NN, Aboussekhra A (2021) Tocilizumab inhibits IL-8 and the proangiogenic potential of triple negative breast cancer cells. Mol Carcinog 60(1):51-59

145. Ruiz-Limón P, Ortega R, de la Rosa IA, del Carmen AbalosAguilera M, Perez-Sanchez C, Jimenez-Gomez Y, PeralboSantaella E, Font P, Ruiz-Vilches D, Ferrin G (2017) Tocilizumab improves the proatherothrombotic profile of rheumatoid arthritis patients modulating endothelial dysfunction, NETosis, and inflammation. Transl Res 183:87-103

146. Knight JS, Luo W, O'Dell AA, Yalavarthi S, Zhao W, Subramanian V, Guo C, Grenn RC, Thompson PR, Eitzman DT (2014) Peptidylarginine deiminase inhibition reduces vascular damage and modulates innate immune responses in murine models of atherosclerosis. Circ Res 114(6):947-956

147. Riganti C, Gazzano E, Polimeni M, Costamagna C, Bosia A, Ghigo D (2004) Diphenyleneiodonium inhibits the cell redox metabolism and induces oxidative stress. J Biol Chem 279(46):47726-47731

148. Massart C, Giusti N, Beauwens R, Dumont JE, Miot F, Van Sande J (2014) Diphenyleneiodonium, an inhibitor of NOXes and DUOXes, is also an iodide-specific transporter. FEBS Open Bio 4:55-59

149. Hasan RN, Schafer AI (2008) Hemin upregulates Egr-1 expression in vascular smooth muscle cells via reactive oxygen species ERK-1/2-Elk-1 and NF-кB. Circ Res 102(1):42-50

150. Ostafin M, Pruchniak MP, Ciepiela O, Reznick AZ, Demkow U (2016) Different procedures of diphenyleneiodonium chloride addition affect neutrophil extracellular trap formation. Anal Biochem 509:60-66

151. Miller MJ, Hamilton SL, Yang L, Pittman SP (2017) Neutrophil FcrRIIA promotes IgG-mediated glomerular neutrophil capture via Abl/Src kinases

152. Matthews J, Wright H, Roberts A, Cooper P, Chapple I (2007) Hyperactivity and reactivity of peripheral blood neutrophils in chronic periodontitis. Clin Exp Immunol 147(2):255-264

153. Matthews J, Wright H, Roberts A, Ling-Mountford N, Cooper P, Chapple I (2007) Neutrophil hyper-responsiveness in periodontitis. J Dent Res 86(8):718-722

154. Cheng OZ, Palaniyar N (2013) NET balancing: a problem in inflammatory lung diseases. Front Immunol 4:1

155 Kirchner T, Hermann E, Möller S, Klinger M, Solbach W, Laskay T, Behnen M (2013) Flavonoids and 5-aminosalicylic acid inhibit the formation of neutrophil extracellular traps. Mediat Inflamm 2013:1-14

156. Handono K, Sidarta YO, Pradana BA, Nugroho RA, Hartono IA, Kalim H, Endharti AT (2016) Vitamin D prevents endothelial damage induced by increased neutrophil extracellular traps formation in patients with systemic lupus erythematosus. Acta Med Indones 46(3):189-198
157. Shi Y, Liu T, Nieman DC, Cui Y, Li F, Yang L, Shi H, Chen $P$ (2020) Aerobic exercise attenuates acute lung injury through NET inhibition. Front Immunol 11:409

158. Gupta AK, Giaglis S, Hasler P, Hahn S (2014) Efficient neutrophil extracellular trap induction requires mobilization of both intracellular and extracellular calcium pools and is modulated by cyclosporine A. PloS One 9(5):e97088

159. Fric J, Zelante T, Wong AY, Mertes A, Yu H-B, Ricciardi-Castagnoli P (2012) NFAT control of innate immunity. Blood J Am Soc Hematol 120(7):1380-1389

160. Witalison EE, Cui X, Causey CP, Thompson PR, Hofseth LJ (2015) Molecular targeting of protein arginine deiminases to suppress colitis and prevent colon cancer. Oncotarget 6(34):36053

161. Knight JS, Subramanian V, O'Dell AA, Yalavarthi S, Zhao W, Smith CK, Hodgin JB, Thompson PR, Kaplan MJ (2015) Peptidylarginine deiminase inhibition disrupts NET formation and protects against kidney, skin and vascular disease in lupus-prone MRL/lpr mice. Ann Rheum Dis 74(12):2199-2206

162. Witalison EE, Thompson PR, Hofseth LJ (2015) Protein arginine deiminases and associated citrullination: physiological functions and diseases associated with dysregulation. Curr Drug Targets 16(7):700-710

163. Willis VC, Gizinski AM, Banda NK, Causey CP, Knuckley B, Cordova KN, Luo Y, Levitt B, Glogowska M, Chandra P (2011) $\mathrm{N}$ - $\alpha$-benzoyl-N5-(2-chloro-1-iminoethyl)-L-ornithine amide, a protein arginine deiminase inhibitor, reduces the severity of murine collagen-induced arthritis. J Immunol 186(7):4396-4404

164. Willis V, Banda N, Cordova K, Chandra P, Robinson W, Cooper D, Lugo D, Mehta G, Taylor S, Tak P (2017) Protein arginine deiminase 4 inhibition is sufficient for the amelioration of collagen-induced arthritis. Clin Exp Immunol 188(2):263-274

165. Kawalkowska J, Quirke A-M, Ghari F, Davis S, Subramanian V, Thompson PR, Williams RO, Fischer R, La Thangue NB, Venables PJ (2016) Abrogation of collagen-induced arthritis by a peptidyl arginine deiminase inhibitor is associated with modulation of T cell-mediated immune responses. Sci Rep 6(1):1-12

166. De Santis M, Mantovani A, Selmi C (2020) The other side of the innate immune system: humoral arms favoring cancer. Cell Mol Immunol 17(10):1024-1025

167 De Rose V, Molloy K, Gohy S, Pilette C, Greene CM (2018) Airway epithelium dysfunction in cystic fibrosis and COPD. Mediat Inflamm 2018:1-20

168. Trivedi A, Khan MA, Bade G, Talwar A (2021) Orchestration of neutrophil extracellular traps (Nets), a unique innate immune function during chronic obstructive pulmonary disease (COPD) development. Biomedicines 9(1):53

169. Khan MA, Ali ZS, Sweezey N, Grasemann H, Palaniyar N (2019) Progression of cystic fibrosis lung disease from childhood to adulthood: neutrophils, neutrophil extracellular trap (NET) formation, and NET degradation. Genes 10(3):183

170. Li P, Li M, Lindberg MR, Kennett MJ, Xiong N, Wang Y (2010) PAD4 is essential for antibacterial innate immunity mediated by neutrophil extracellular trapsPAD4 in NET-mediated bacterial killing. J Exp Med 207(9):1853-1862

171. Jha V, Chugh KS (2002) Posttransplant infections in the tropical countries. Artif Organs 26(9):770-777

172. Nau R, Tauber S (2008) Immunomodulatory properties of antibiotics. Curr Mol Pharmacol 1(1):68-79

173 Manda-Handzlik A, Bystrzycka W, Sieczkowska S, Demkow U, Ciepiela O (2016) Antibiotics modulate the ability of neutrophils to release neutrophil extracellular traps. Respiratory treatment and prevention. Springer, Cham, pp 47-52

174. Mutua V, Gershwin LJ (2021) A review of neutrophil extracellular traps (NETs) in disease: potential anti-NETs therapeutics. Clin Rev Allergy Immunol 61(2):194-211 
175. Martinez NE, Zimmermann TJ, Goosmann C, Alexander T, Hedberg C, Ziegler S, Zychlinsky A, Waldmann H (2017) Tetrahydroisoquinolines: new inhibitors of neutrophil extracellular trap (NET) formation. ChemBioChem 18(10):888-893

176. Khan MA, Palaniyar N (2017) Transcriptional firing helps to drive NETosis. Sci Rep 7(1):1-16

177. Khan MA, D’Ovidio A, Tran H, Palaniyar N (2019) Anthracyclines suppress both NADPH oxidase-dependent and-independent netosis in human Neutrophils. Cancers 11(9):1328

178. Martinod K, Fuchs TA, Zitomersky NL, Wong SL, Demers M, Gallant M, Wang Y, Wagner DD (2015) PAD4-deficiency does not affect bacteremia in polymicrobial sepsis and ameliorates endotoxemic shock. Blood J Am Soc Hematol 125(12):1948-1956

179. Sørensen OE, Clemmensen SN, Dahl SL, Østergaard O, Heegaard NH, Glenthøj A, Nielsen FC, Borregaard N (2014) Papillon-Lefevre syndrome patient reveals species-dependent requirements for neutrophil defenses. J Clin Investig 124(10):4539-4548

180. Subramanian N, Torabi-Parizi P, Gottschalk RA, Germain RN, Dutta B (2015) Network representations of immune system complexity. Wiley Interdiscip Rev Syst Biol Med 7(1):13-38

181. Carbone J, Sarmiento E, Rodriguez-Molina J, Fernandez-Cruz E (2004) Atypical presentation of common variable immunodeficiency without infections. Allergol Immunopathol 32(4):218-222

182. Klopf J, Brostjan C, Eilenberg W, Neumayer C (2021) Neutrophil extracellular traps and their implications in cardiovascular and inflammatory disease. Int J Mol Sci 22(2):559

Publisher's Note Springer Nature remains neutral with regard to jurisdictional claims in published maps and institutional affiliations. 